The conclusion that the "new system" of hurrying conval. escents out to mingle with those susceptible to scarlet fever is better than the "old system" because it kills no more than the "old system," is, to say the least, a poor argument for the new.

The most infectious or contagious period of scarlet fever I believe to be when the rash is at its height, but the time when it is most frequently conveyed to others is during the desquamation period. This is because children, while desquamating and afflicted with other complications, are permitted to mingle with other children. The cast-off skin, I believe, is capable of conveying the disease when carried in clothing, letters and other methods of conveyance. Why should not the skin be charged with infection as well as the mucous membrane? To the eye the manifestation of the disease in the skin is as apparent as elsewhere. What influence makes the skin in these cases harmless and leaves the mucous membrane a source of danger? The skin is in all probability the major channel through which the infection leaves the body. Reason and experience teach that this cast-off skin contains the element which produces scarlet fever. If a shirt worn becomes infected. why should not the skin, which is a still closer covering, become infected? It is doubtful if there is a practical method of disinfecting the inner or under side of the skin before it is detached.

You will observe that there were no "returns" of the disease in the 33 cases of Dr. Lauders, which were "free from peeling and complications" before restrictions were removed. Would it not be better to take these 33 cases as a source of inspiration and say unequivocally that all cases of scarlet fever should be isolated until there is freedom from complications and until desquamation is completed?

Heman Spalding, M.D.,
Chief Medical Inspector, Department of Health.

\section{As Others See Us.}

ErmhuRst, Itu., July 17, 1904.

To the Editor:-.-Apropos of the article appearing in Printers' Ink, the subject of your editorial comment in THE Jour. NAL, July 16, I wish to call attention to the fact that it is highly satisfactory to dispense one's own remedies and in this manner antagonize the evil of copied prescriptions, unsanctioned refills and substitution. It is not only more remunerative, but also more satisfactory to both physician and patient. It enables the physician to follow the disease more closely, to note the therapeutic results, whether positive or negative, and it gives a sense of security to know your patient is not receiving a sophisticated or substituted preparation of medicine. With the numerous tablet preparations of tried formulas and of alkaloids, it becomes an easy matter to dispense one's own drugs. A complete stock of drugs can be obtained for about $\$ 75$. This includes such expensive drugs as protargol, urotropin, creosotol, adrenalin, etc. Any physician whose practice does not exceed $\$ 3,500$ annually can find time to dispense all of his drugs. If more physicians would dispense their own remedies and do their own thinking we would hear less of therapeutic nihilism.

H. F. L.

\section{Wisconsin Medical Society Proceedings.}

Micwauree, Wrs., July 11, 1904.

To the Editor:-I beg leave to call your attention to an error in the report of the recent meeting of the Wisconsin State Medical Society in The Tournal, July 2, page 65. The paragraph referred to reads that "A contract was made with the Milwaukee Medical Journal for the publication of the proceedings of the society for the ensuing year on the same terms as preceding contract." This contract has been made with the Wisconsin Medical Jonmal. ARTHUR J. PATEK, Editor Wisconsin Medical Journal.

\section{Cataractous Families.}

Fond DU LAC, WIS., July 14, 1904.

To the Editor:-At the suggestion of Dr. John L. Dickey I wish to add another case to his as an instance of the hereditary tendency to cataracts. While I have not sufficient data at hand to thoroughly convince me that heredity should be classed among the causes of cataracts, nevertheless my experience has been such as to make me think of it as a possible cause. I am pleased to learn that some one is investigating the subject and as evidence $I$ report a case wherein the mother, a son, a daughter and a grandson are all afficted with partial cataracts. The mother is 64 , the son and daughter respectively 36 and 32 , and the grandson 10.

Dr. G. N. Brazeau.

\section{The Oldest Students' Medical Club.}

BALtimore, July 12, 1904.

To the Editor:-I should be glad to learn through THe Jourral the name and date of foundation of the oldest students' medical club in this country. The Rush Medical Club, a quiz club among the undergraduates of the School of Medicine of the University of Maryland, was founded in April, 1850 , and has had an unbroken existence to the present time. Eugene F. Corderc, M.D.

\section{Queries and Minor Notes.}

Anonymous Communications will not be noticed. Queries for this column must be accompanied by the writer's name and ad. dress, but the request of the writer not to publish his name will be faithfully observed.

EFFECT OF CIIMATE ON CHRONIC CATARRHAL DEAFNESS

\section{-_......, Mins,. July 11, 1904}

To the Editor - Would the editor kindly give information regarding climatic effect on chronic catarrhal deafness? Might one expect relief or cure by changing climate from Minnesota to Southern California or to tropical islands? Take, for instance, a case that has progressed for several years and has reached a stage where a watch can be heard only in contact, tubes closed and drums re tracted. E. W. $W$.

ANswer. - In the early stages of catarrhal inflammation of the eustachian tube and middle ear, some improvement may be obtained by removal to a warmer and drier atmosphere, but in such a case as our correspondent describes no relief could be expected from the change of climate.

\section{TIME TO TAKE AIKALIES TO MAKE URINE ACID.}

J. W. B. of Virginia writes: During an examination of the state medical board the following question was asked: "At what time-1. e., beiore or after meals-should an alkall be given in order to render the urine actd?" Please answer and give the reaction that takes place.

\section{MATERNITIES FOR THE UNMARRIED.}

L. I. C. of Wisconsin : After using your Ietter in The JournaL July 2. we destroyed the note giving your name and address. We have receiver some communications for you.

\section{Deaths.}

D. Peter Belew, M.D., died at his home in Edinburg, Va., July 10 , aged 85 .

Samuel M. Trinkle, M.D., 1872, died at his home in Philadelphia of apoplexy, July 1, aged 64 .

Albert E. Ahlstrom, M.D. University of Minnesota, 1900, died at his home in Cokato, Minn., July 3.

Hamilton Fish, M.D. Denver College of Medicine, 1893, died, July 12, at his home in Denver, from gastroenteritis.

David J. Fitzgerald, M.D. College of Physicians and Surgeons, N. Y., 1884, died at his home in Glens Falls, New York, July 17, aged 46 .

Eli J. Zook, M.D. Jefferson Medical College, Philadelphia, 1878, died at his home in Newville, Pa., of heart disease, July 11 , aged 60 years.

Gideon D. Hobart, M.D. Bellevue Hospital Medical College, New York City, 1873, of Brooklyn, N. Y., died at Elizabethville, N. Y., July 15 , aged 59 .

Victor Steinberger, M.D. College of Physicians and Surgeons, New York, 1896, a member of the New York County Medical Society, of New York City, was drowned in Jamaica Bay, July 17 , aged 30 . 